\title{
La energía nuclear, una alternativa de sustentabilidad para resolver la demanda eléctrica en México. (Segunda parte)
}

\author{
S.D. Bazán-Perkins \\ División de Estudios de Posgrado \\ Facultad de Ingeniería \\ E-mail: bazanperkins@ hotmail.com
}

(recibido: enero de 2004; aceptado: diciembre de 2004)

\begin{abstract}
Resumen
La actual política energética propicia un alto riesgo en la economía de México al no promover la expansión de la generación eléctrica mediante fuentes de energía alternas, como geotérmica, eólica, solar, biomasa, hidrógeno y nuclear. Por el contrario, se da prioridad al empleo del gas natural, ocasionando su desabasto, decremento de las reservas probadas y el aumento de su importación. En este sentido, y ante el descenso de la producción nacional de gas de 1999-2002, la prin cipal expectativa se centra en obtener un abastecimiento suficiente a precios bajos de las supuestas grandes reservas comerciales de las Cuencas de Burgos y Chicontepec. Sin embargo, desde los años 50's se confirmó que los campos de gas natural de la Cuenca de Burgos cuentan con un potencial geológico menor al de los del Sur de Texas. También, desde los 60's se encontró que los campos de gas-aceite de la Cuenca de Chicontepec requerían de costosas técnicas de producción para su aprovechamiento, debido a su baja permeabilidad. Primero, la Comisión de Energéticos (1976) y más reciente PEMEX (2003), del 2003-2005 pronostican el descenso de la producción nacional de hidrocarburos al no integrarse con oportunidad nuevos campos productores. Se analiza la existencia de escasas probabilidades para encontrar a corto plazo significativos campos de hidrocarburos comerciales, como sería en la región de aguas profundas del Golfo de México. El objetivo principal de este trabajo es proponer la diversificación en el consumo de energéticos de México con nuevas fuentes de abastecimiento, basadas en la energía nuclear y las fuentes renovables. Entre las actividades iniciales, estaría concluir la evaluación económica de las reservas potenciales de uranio jurásico de la Cuenca de Tlaxiaco y terciario de la Cuenca de Burgos, que facilitarían la oportunidad de producir energía barata y limpia en condiciones de competitividad al disponer de reservas de uranio de gran volumen.
\end{abstract}

Descriptores: Electricidad, hidrocarburos, gas natural, petróleo, uranio, renovables, eólica, hidroeléctrica, geotérmica, reservas y producción.

\footnotetext{
Abstract

The pres entenergy pol icy causes a high risk in theecon omy of $M$ ex ico when not pro mot ing theex pansion of the ca pacity on the gen er a tion of electricity by means of alternative power plants such as geother mal, aeolian, so lar, biomass, hy drogen or nu clear. Even more, it is based mainly on a large consump tion of nat u ral gas causing theac cel er ated decrement of thedo mestic proven reserves and thefast as cent of its im ports. Due tothereduction of 1999-2002 on thena tional gas production, themain ex pecta tion iscentered on getting suffi cient supplies atcom peti itiveprices from the great com mer cial re serves in the Ba sins of Burgos and Chicontepec. However, since the fiftiesit was con firmed that the natu ral gas fieldsfrom theB $B$ sin of Burgos havemi nor geo logicpoten tialthan those of the South of Texas.
} 
In ad dition, sincethesixties itwas known that the gas- oil fields of the $B$ a sin of Chicontepec re quired ex pen sivetech niques of pro duc tion for their harnessing. The for mer "Comisión de En ergéticos" (1976) and themore recent PEM EX (2003), foretell the cut back of thena tional pro duction of hy dro car bons when not in tegrat ing opportun ely new pro duc ing fields. It is beingan a lyzed theex istence of slight proba bilities offinding, in the short term, signifi cant commer cial hy drocar bon fields as itcould be the case in the deep wa ter region of the G ulf of $M$ ex ico. Theaim of this pa per is to pro posethedi versification on theen ergy con sump tion in M ex ico us ing new sources based on nu clear en ergy and therenew a ble sources. A mong theini tial activi ties, would be that of concluding theeco nomic eval $u$ a tion of thepo tential re serves of ju ras sic ura nium of the Ba sin of Tlaxiaco and ter tiary of the B a sin of Burgos. B oth of which, would fa cil i tatean op por tu nity to pro duceclean and cheap en ergy in con di tion sof com pet i tive ness by having great vol umeura nium reserves.

Keywords: Electricity, hy dro car bons, nat u ral gas, petro leum, ura nium, renewable, aeolian, hy droelectric, geother mal, reservesand production.

\section{Introducción}

En la primera parte de este artículo se analizó la importancia de la energía eléctrica en las economías actuales. También las tendencias tecnológicas y de los mercados de energéticos de principios del siglo XXI, orientados a mejorar la producción de electricidad de un modo sustentable, empleando fuentes de energía como las renovables, nuclear y el hidrógeno. El propósito es la preservación del ambiente mundial, mediante tecnologías que aceleren el progreso humano. Estas opciones tecnológicas son una mejor alternativa ante el incremento de los precios de los hidrocarburos en el mercado internacional, particularmente el del gas natural, que ya no será un energético de precios bajos. Como se analizó en la primera parte del artículo, las plantas nucleoeléctricas de III generación, presentan una tendencia decreciente en sus costos de generación, alcanzando en la actualidad altos niveles de competitividad. Para el 2003, sus costos de generación son equiparables en México a las nuevas plantas de ciclo combinado a base de gas. Igualmente, del conjunto de opciones tecnológicas proyectadas al 2015, se encontró que el Pebble Bed Modular Reactor (PBMR) podría ser una opción tecnológica para implementarse en México por su bajo costo de generación de 1.6 фUS/kWh, construcción modular en corto tiempo ( 2 años) y alta seguridad, disponibles hacia el 2013. De este modo, se planteó la necesidad de desarrollar en México un programa energético a largo plazo para transformar su actual economía basada en el petróleo a una economía basada en el hidrógeno, hacia el 2030, por ser el tiempo de duración estimado de las reservas convencionales de petróleo crudo en el mercado mundial, según investigaciones de varios analistas. En esta segunda parte, se analiza la disponibilidad de los recursos energéticos primarios comerciales de México para la generación eléctrica a corto y mediano plazo. También las probabilidades de encontrar nuevas reservas de hidrocarburos significativas en las aguas profundas del Golfo de México. Se describe en términos generales, el potencial de las reservas de uranio en México para su aprovechamiento a mediano plazo. Finalmente, se analizan las ventajas y desventajas de las fuentes de energía renovables. Su mayor empleo se podría incrementar en menor tiempo al dársele mayor peso a la generación nucleoeléctrica.

\section{Capacidad de generación eléctrica actual}

\section{Panorama nacional para la generación de electricidad}

Entre los puntos debatibles de la actual política energética de México se encuentra el desarrollar una expansión eléctrica con mayor empleo de combustibles fósiles, que propician las mayores afectaciones ambientales. Bauer y Quintanilla (2000) al analizar la expansión del sector eléctrico de 1997-2006, concluyeron que la notoriedad del aplazamiento del empleo de las fuentes no fósiles entra en contradicción con los compromisos nacionales e internacionales para aminorar las emisiones de gases de efecto invernadero, tanto a nivel local como global 
Como ha sido descrito por SENER (2001), en el 2000 la generación eléctrica de 192,764 GWh se obtuvo en un $75 \%$ de los combustibles fósiles (46.7\% petróleo, $11.8 \%$ gas y $16.7 \%$ carbón mineral y dual) y para el 2010 se estiman 329,448 GWh, de los cuales un $83 \%$ ( $54 \%$ gas, $23 \%$ petróleo y $6 \%$ carbón mineral), ver figura 5 . Esto es, el empleo de los hidrocarburos en la producción de electricidad se incrementará de $58.5 \%$ a $77 \%$. Por lo cual, es importante conocer sus posibilidades de suministro con reservas domésticas, como enseguida se expone.

\section{Disposición de recursos energéticos primarios para la generación de electricidad en México}

En México, la seguridad del suministro de los recursos energéticos para generar electricidad plantea serios problemas, debido al acelerado agotamiento de sus reservas de hidrocarburos y el alto avance de su explotación (madurez). Aunado a las dificultades geológicas y técnicas que repercuten en altos costos para aprovechar el $40 \%$ de las reservas, ubicadas en la Región Norte, y en particular, los de la Cuenca de Chicontepec (Figuras 13 a la 20 y tablas 2 y 3 ).

A lo anterior, se suma la baja calidad del carbón mineral del país en mantos delgados y plegados, así como su alto costo comercial que conlleva a su bajo aprovechamiento (González-Reyna, 1956) y la falta de desarrollo tecnológico y de recursos humanos para emplear el uranio doméstico. Por ello, en la actualidad se acude al comercio exterior para proveer materias de generación de electricidad, como ocurre con el gas natural, carbón mineral, gasolinas y combustible nuclear de las que México es importador, implicando dependencia energética externa y fuga de divisas.

Estas conclusiones conllevan a considerar un cambio en la política energética del país para remplazar las actuales tecnologías de generación eléctrica, basándose en los hidrocarburos por la disponibilidad confiable y suficiente a precios razonables, con menores impactos al ambiente y de alto progreso humano.

\section{Las reservas de petróleo en México}

La seguridad en el suministro de hidrocarburos de México, en sus distintas modalidades como es el petróleo crudo, líquidos del gas y el gas seco, se refleja en la variación anual de sus reservas probadas, probables y posibles. Durante el período 1980-1984, se obtuvo el mayor incremento de las reservas de hidrocarburos, al pasar de 45,803 millones de barriles a los 72,500 millones de barriles, esto equivale a un $58.2 \%$ de aumento. Desde entonces, es decir, desde 1984, las reservas totales de hidrocarburos del país decrecen año con año (Figura 13).

A su vez, recientemente la estructura de las reservas de hidrocarburos del país se han deteriorado sustancialmente con la caída de sus reservas probadas. En efecto, entre 1999 al 1 de enero del

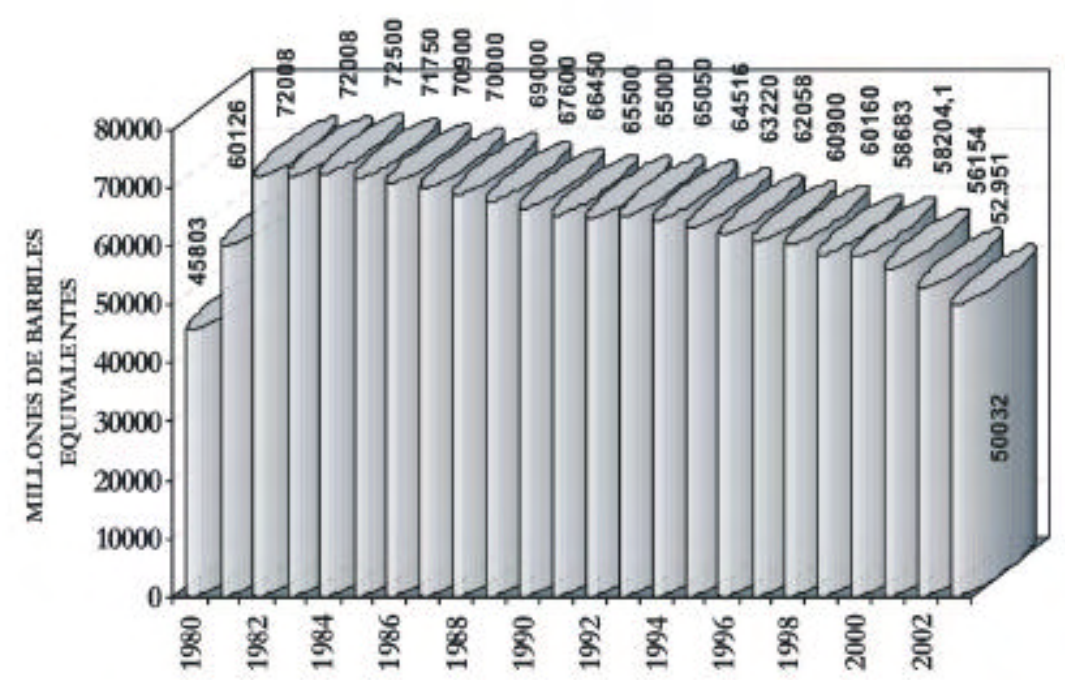

Figura 13. Evolución del nivel de reservas totales de hidrocarburos en M éxico, 1980-2003 [Elaboración propia con datos de la SENER (2001) y PEMEX (2003)] (M illones de barriles equivalentes) 
2004, las reservas probables y posibles crecen en un 51 y $22 \%$ respectivamente, mientras tanto, las probadas se reducen en un $46 \%$. La discrepancia se debe a que no existió, en su oportunidad, suficiente inversión en exploración para incrementar a los ritmos adecuados las reservas probadas, a partir de las probables y posibles o mediante la incorporación de nuevos campos (Figura 14).

Esta situación, también repercute desde 1995 en el acelerado decremento de las reservas probadas de petróleo crudo de México, reportadas por la EIA (2003), con fuertes caídas en el 2000 y 2003. En
1995, se reportan 50,776 millones de barriles que en aquel entonces garantizaban por unos 53 años la producción. Sin embargo, al primero de enero del 2003 se ubican en 12,622 millones de barriles y con la producción del 2003, su tiempo de duración es de apenas 10 años (Tabla 2).

El mayor decremento histórico de las reservas probadas de petróleo crudo del país acontece en el 2003; tal como fue expuesto en prensa nacional el 20 de enero por Suárez (2003), director Corporativo de Finanzas PEMEX. Aclaró que las reser-

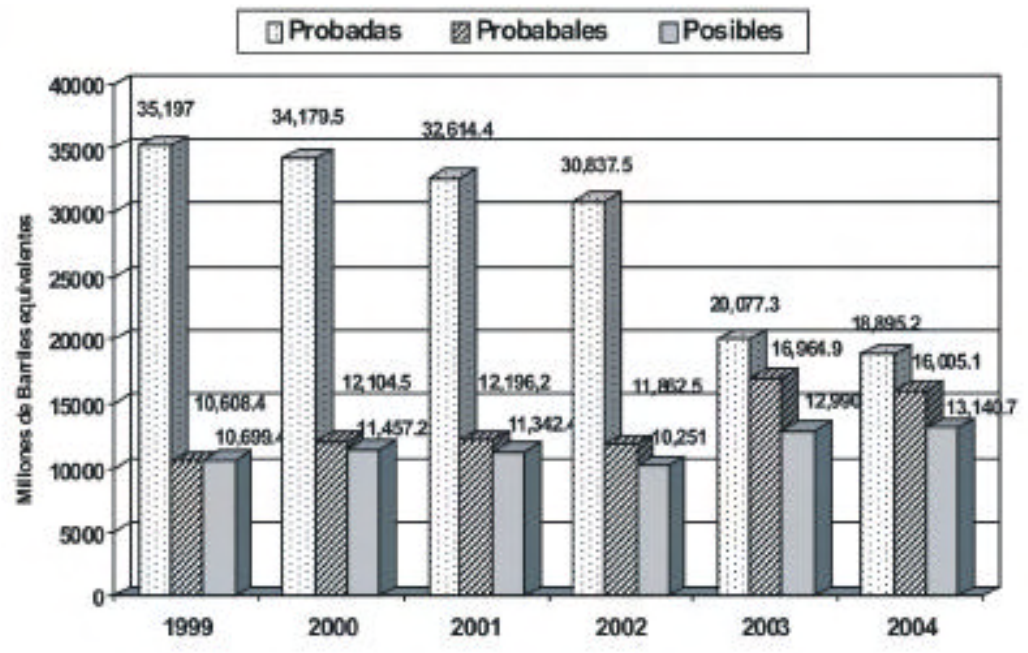

Figura 14. Estructura de las reservas de hidrocarburos en M éxico, 1998-2003, (reservas al inicio del año). [E laboración propia con datos de PEMEX (2001, 2002 y 2003) / A nuarios y memorias)

Tabla 2. Reservas probadas de petróleo crudo, producción anual y tiempo estimado de duración en M éx ico [Elaboración propia con datos de EIA (2003), PEM EX (2001, 2002 y 2003) e INEGI (1993, 2001, 2002 y 2003)]

\begin{tabular}{ccccc}
\hline & Reservas probadas & \multicolumn{3}{c}{ Producción } \\
Año & Millones de barriles & Miles de barriles al día & Millones de barriles anuales & Años de duración \\
\hline 1992 & 51,298 & $2,667.7$ & 973 & 52 \\
1993 & 51,298 & $2,673.4$ & 975 & 52 \\
1994 & 50,925 & $2,685.1$ & 980 & 51 \\
1995 & 50,776 & $2,617.2$ & 955 & 53 \\
1996 & 49,775 & $2,858.3$ & 1,043 & 47 \\
1997 & 48,796 & $3,022.2$ & 1,103 & 44 \\
1998 & 40,000 & $3,070.5$ & 1,120 & 35 \\
1999 & 47,822 & 2,906 & 1,060 & 45 \\
\hline
\end{tabular}


Tabla 2. Reservas probadas de petróleo crudo, producción anual y tiempo estimado de duración en M éx ico [Elaboración propia con datos de EIA (2003), PEM EX (2001, 2002 y 2003) e INEGI (1993, 2001, 2002 y 2003)] ...continuación

\begin{tabular}{ccccc}
\hline & Reservas probadas & \multicolumn{3}{c}{ Producción } \\
Año & Millones de barriles & Miles de barriles al día & Millones de barriles anuales & Años de duración \\
\hline 2000 & 28,399 & 3,012 & 1,099 & 25 \\
2001 & 28,2600 & 3,127 & 1,141 & 24 \\
2002 & 26,941 & 3,177 & 1,159 & 23 \\
$\mathbf{2 0 0 3}$ & $\mathbf{1 2 , 6 2 2}$ & $3,370.9$ & 1,230 & $\mathbf{1 0}$ \\
\hline
\end{tabular}

vas de petróleo crudo probadas, eran de 12,622 millones de barriles al excluir de plano a las no desarrolladas de la región de Chicontepec, ya consideradas, se incrementaron en 18,767 millones de barriles. Por otra parte, anunciaba también la caída de la producción de hidrocarburos de los yacimientos de Cantarell después del 2004. En efecto, a mediados del 2003 la EIA y BP reportan en la estadística mundial de reservas probadas de petróleo crudo por país, que las de México eran de 12,6222 millones de barriles, referidos al 1 de enero del 2003. Por tanto, México pasó por sus reservas de petróleo en el mundo del décimo al decimocuarto lugar.

\section{Las reservas de hidrocarburos de la región Norte y sus implicaciones en el sector eléctrico}

La problemática económica de la Región Norte es que además de contar con el $40 \%$ de las reservas totales de hidrocarburos del país, su producción de petróleo crudo es decreciente y mínima, en 2002 representó el 1.4\% del total (Figura 15). Sin embargo, en la próxima década se requerirá elevar su producción a fin de cubrir las necesidades energéticas del país, en particular, la del sector eléctrico, que hacia el 2010 dependerá al menos de un $77 \%$ del petróleo y gas. Las perspectivas de la viabilidad económica de los campos de la Región Norte (Cuenca de Chicontepec), se definen por sus características geológicas, las tecnologías disponibles y el nivel de inversión para su desarrollo. Para servir de base a la presente discusión, se consideran dos posibles escenarios económicos, como reservas convencionales y otra como no convencionales, los cuales se exponen en seguida.

Si se plantean las reservas de Chicontepec, como reservas de hidrocarburos convencionales, significa que como tal, tendrán la capacidad para cubrir los decrementos de la producción, que acontece en la mayoría de las regiones productoras del país, y así mantener los niveles de producción. En esta situación, podrán compensar por lo menos, el descenso de la capacidad de producción de los campos de Cantarell esperada para el 2005 (Figuras 15 y 19).

En cambio, si los campos que quedan por explotar de la Región Norte (Cuenca de Chicontepec) son de tipo no convencional, entonces su aprovechamiento será mínimo hasta que hacia el 2030 se estén agotando las reservas mundiales de hidrocarburos convencionales, y entonces, ante un mercado de hidrocarburos de precios altos podría alcanzar la competitividad comercial. Los argumentos que sostienen este modelo son los más sólidos y se relacionan con el comportamiento de la curva logística de producción; así como a la naturaleza geológica de la región, como se expone a continuación.

Campbell (2000) concluye que el descubrimiento de un campo de hidrocarburos de tipo convencional en una economía de mercado, se identifica por su patrón de producción en forma de campana. El modelo se refiere a la curva de producción de Hubbert, que inicia en forma logarítmica y obtiene un máximo cuando se han extraído poco menos de la mitad, para después entrar en rápida declinación. Resulta evidente, 
como se muestra gráficamente en la figura 15 , que la producción de la Región Norte ha estado en decremento y no corresponde a este modelo, aún con períodos de precios altos del petróleo no se incrementa su producción.

En general, se puede afirmar que la curva de producción de Hubbert se ha cumplido para todos los campos de hidrocarburos convencionales, por región, por país y a escala mundial, cuando se sujetan a la política energética de una economía de mercado. En México, como ejemplo, tal comportamiento se apreció en la producción histórica de la Faja de Oro, dentro de la misma Región Norte. La producción de La Faja de Oro, formó la curva típica en forma de campana de 1915 a 1932; su producción máxima se alcanza en 1921 con 193,397,587 barriles, que llevó a México a ocupar el segundo lugar en producción mundial, después su producción decrece para alcanzar en 1932 un nivel menor comparable al de 1915 (Figura 16).

De la Fuente y Mejia Isidro (1969) realizaron el estudio geológico y económico de los campos de gas-aceite de la Cuenca de Chicontepec. Estos autores determinan las limitantes de su viabilidad debido a la consistente falta de permeabilidad de la roca. Las altas dificultades en la perforación conllevan a una labor de lento avance y frecuente abandono de la operación. También, muestran una falta de continuidad de los campos que se interrumpen a corta distancia en virtud de los cambios de facies en los sedimentos del Jurásico Superior. Por otro lado, en las pruebas de producción no hay flujo de hidrocarburos por falta

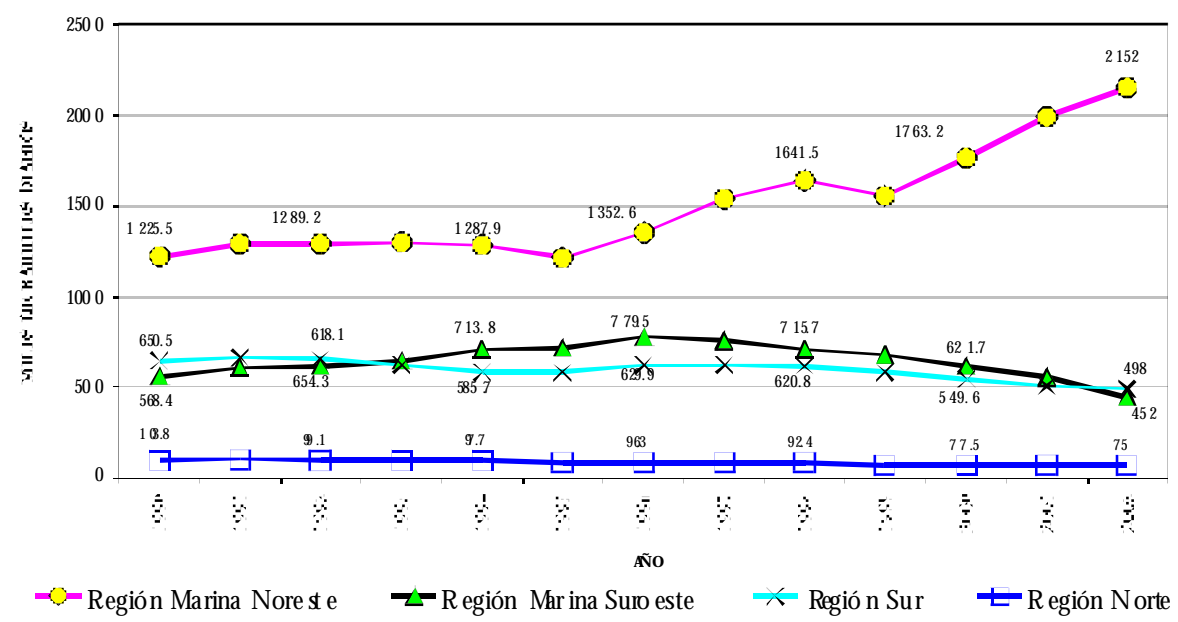

Figura 15. Producción de petróleo crudo por región geográfica en M éxico, 1990-2002. [Elaboración propia con datos de PEMEX 2003 y 2002) / Exploración Producción, anuario (2001 y 2002)]

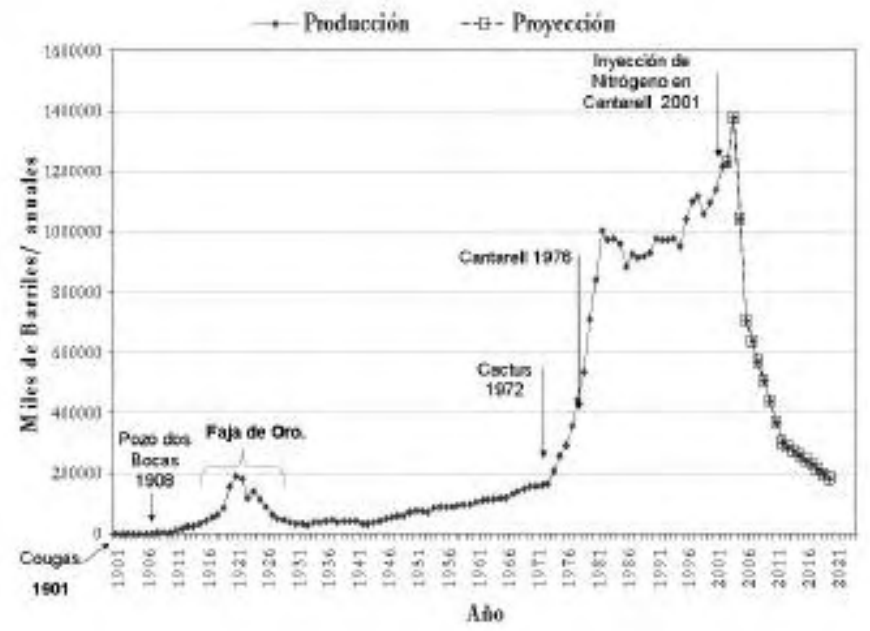

Figura 16. Evolución histórica de la producción de petróleo en M éxico, 1901-2002; y su proyección al 2020 [Elaboración propia con datos de INEGI (2003) y PEMEX 2003)] 
de permeabilidad de la roca; por tanto, los hidrocarburos son básicamente gas y muy poco aceite ligero que fluyen mezclados con agua salada.

Por sus características geológicas y los resultados de las pruebas de producción, los campos de hidrocarburos de la Cuenca de Chicontepec difícilmente podrían llegar a tener a corto y mediano plazo, un papel significativo como reservas convencionales. A diferencia de los campos marginales de Alberta Canadá recién integrados a las reservas mundiales (EIA, 2003), los de la paleotrinchera de Chicontepec son campos de escasa continuidad lateral, por ser la roca almacenadora de flysch; rápidos cambios litológicos laterales y verticales acompañados de acuñamiento, los configuran como microcampos discontinuos, aislados y de formas irregulares, difícil de cubicar con exactitud y costos de producción altos. En adición, para la nula permeabilidad de la roca en las zonas no fracturadas, se requiere de tecnologías costosas para fracturarla (hidráulico o plowshare, figura 17). Estos factores elevan los costos para ser aprovechables en gran escala comercial, mientras existan en el mercado internacional reservas de hidrocarburos convencionales.

\section{Dinámica de los niveles de reservas y de la capacidad de producción de hidrocarburos}

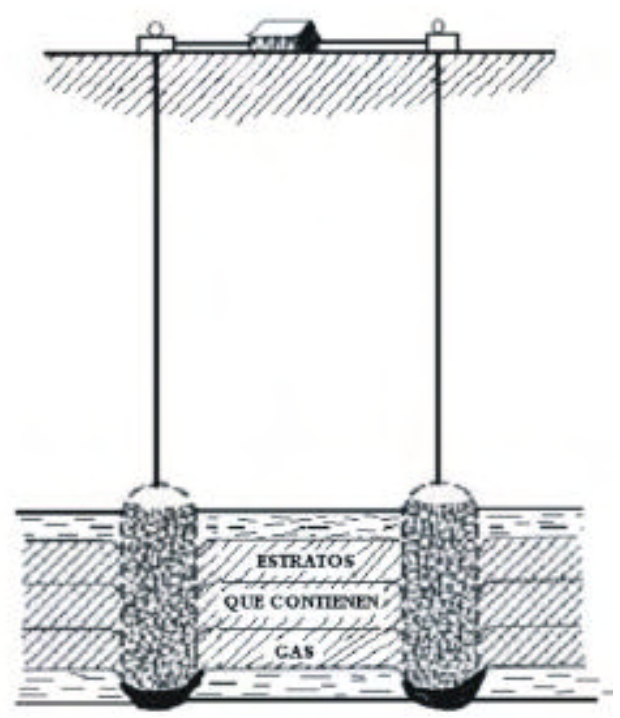

Del análisis de la evolución decreciente de los niveles de reservas probadas y de la capacidad de producción de los campos de hidrocarburos, se estima que hacia el 2010, el país ya estará importando petróleo crudo. El primer método se ilustra en forma gráfica en la figura 18, construida con los datos de la tabla 2. El análisis comprende el nivel de reservas probadas en años, desde 1990 al 1 de enero del 2003, a excepción del aumento en 1999 se tiene un comportamiento regular de decremento. Este comportamiento, al ser ajustado a una proyección lineal, define que al año 2009, la producción habrá igualado el monto de las reservas. Por tanto, hacia el 2010 se estará importando el energético si se mantiene la capacidad de producción a los niveles de 2002 y si no se incrementa en forma significativa la producción de la Región Norte.

Otra apreciación se obtiene de la capacidad de producción que se espera de los campos de hidrocarburos de Cantarell contra la demanda interna, basándose en la información expuesta por Suárez (2003) y suponiendo que el resto de los campos mantienen su proporción de producción y no se eleva en gran medida la producción en la Cuenca de Chicontepec, resulta que al 2009 se estará importando petróleo (Figura 19).
Una chimenea de material permeable muy triturado creado por una explosión nuclear puede aumentar la productividad de los pozos de gas natural en una formación poco permeable. La explosión nuclear producirá un gran "pozo" en el que se almacenaría el gas y del que sería bombeado a la superficie.

(Adaptado de Gerber Carl R. et al,.1966)

Figura 17. M étodo Plowshare 


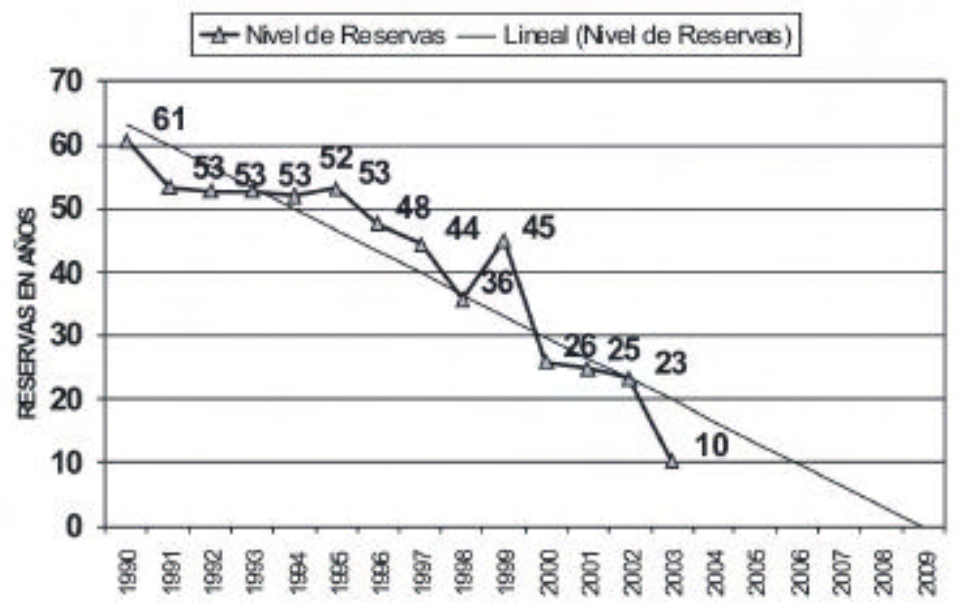

Figura 18. Reservas probadas de petróleo crudo en M éxico, 1990-2003. [Elaboración propia con datos de EIA (2003); PEMEX (2003) (años de duración) ]

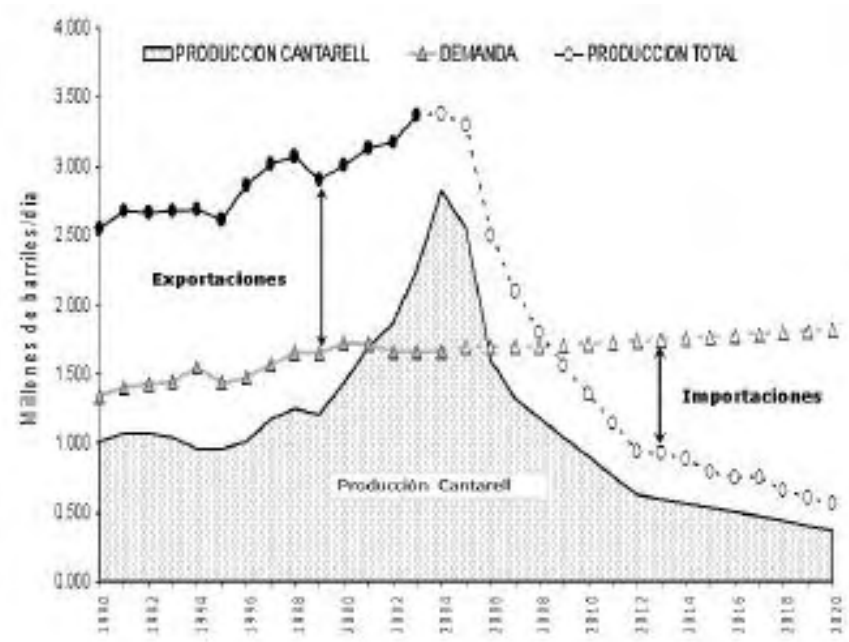

Figura 19. Petróleo producido y consumido en M éxico de 1990-2003 y su proyección al 2020. [Elaboración propia con datos de Suárez-Coppel (2003), INEGI (2003) y PEMEX (2002 y 2003 a y b) ]

Por todo lo expuesto, se concluye que hacia el 2010, el escenario energético del país estará determinado por la insuficiencia de hidrocarburos. Esto es, que desde el año 2000 era oportuno iniciar la construcción de plantas nucleares de III generación, en sustitución de las termo eléctricas a base de combustibles fósiles y para la expansión de la capacidad de generación de electricidad.

\section{Las reservas de gas natural en México}

De fundamental importancia para la economía del país sería la generación de electricidad mediante recursos energéticos domésticos, los cuales propicien altos niveles de desarrollo tecnológico a costos razonables y de mayor efecto multiplicador hacia todos los sectores de consumo. Esta posibilidad de alcanzar una producción competitiva, permitirá generar excedentes para su exportación, por su calidad, cantidad y limpieza. Este conjunto de condiciones de sustentabilidad no podrían ser alcanzadas en México basándose en los combustibles fósiles, en particular con el gas natural, que al emplearlo en la generación eléctrica, afecta al ambiente en un $22 \%$ del calentamiento global.

En efecto, el escenario actual de los campos productores del gas natural en México es su insuficiencia de reservas probadas para sostener la actual producción por más de 7 años, y con escasas posibilidades de incrementarlas en forma significativa en Chicontepec y Burgos. También, 
desde 1999-2002, la producción de gas natural está en franco decremento por el estado avanzado de explotación de los yacimientos. Aunado a la intensificación de la volatilidad al alza de los precios del gas natural en el mercado americano, en las que ya no será un combustible barato. Todo esto repercute en que de no modificarse a corto plazo la actual política energética de México, orientada a intensificar la generación eléctrica basándose en el gas natural, se incrementará el riesgo de la seguridad energética del país.

Dentro de los tres primeros años del presente siglo, las reservas probadas de gas natural de México ya registran significativas reducciones. Hacia el 2002 se cubican 38.95 trillones de pies cúbicos (Tpc), en el 2003 se reportan 8.776 Tpc, para mantener al país en el cuadragésimo lugar en el mundo, que sería apenas para 7.1 años. El descenso se da desde el 2000, cuando se valoraban $43 \mathrm{Tpc}$ de reservas probadas de gas y ubican al país en decimoquinto lugar en el mundo (BP, 2000 y 2003). Así, por ejemplo, las reservas de gas natural probadas de México en el 2003 se reducen al $20 \%$ de las valoradas en el 2000 , que infieren fallas técnicas y de cálculo. Desglosadas en cifras de 2000, las reservas totales eran de 78.286 Tpc, de las cuales 43.167 Tpc se determinaban como probadas, 14.884 Tpc como probables y 20.233 Tpc como posibles (Silva 2001, en Arriola 2001).

La principal expectativa para el mercado del gas natural en México, se fundamenta en la posibilidad de incrementar las reservas y su producción en la Cuenca Terciaria de Burgos (Tamaulipas), en grandes volúmenes y a precio bajo. Este supuesto se basó en una comparación del número de pozos desarrollados en la exploración de gas al Sur de Texas, Estados Unidos, que en gran proporción son mayores a la Cuenca de Burgos; por lo mismo, se propuso desarrollar un programa de perforación similar y así cubrir la demanda nacional. Sin embargo, existe inconsistencia geológica y de menor marco de posibilidades, debido a que desde los años 50's las supuestas similitudes potenciales de ambas regiones quedaron anuladas al comprobarse cambios litológicos y tectónicos derivados de la información geológica y geofísica (Tabla 3).

En efecto, en las clásicas "Notas Sobre la Geología Petrolera de México" de Benavides (1956) razonaba que ya desde 1934, se sabía que la Cuenca de Burgos, aunque es la misma estructura de los yacimientos del Suroeste de Texas, los campos de gas se empobrecen hacia el territorio de México por ser más pequeños y distribuirse en forma más aislada, debido a los abruptos cambios por fallamiento, reducción de las facies sedimentarias y cambios en los ambientes de formación. En donde su producción inicial es alta pero su declinación ocurre rápidamente. En este sentido, los mejores campos serían los que se encuentran próximos a la frontera con los Estados Unidos (Reynosa, Misión, La Presa, Treviño, 18 de Marzo y otros) que se restringen y diluyen hacia el territorio de México, hasta prácticamente desaparecer.

En la práctica, las proyecciones que auguraban grandes incrementos en la producción de gas natural en México, con base a las posibilidades de la Cuenca de Burgos, se modifican bastante ante el decremento de la producción nacional. En efecto, a

Tabla 3. Principales reservas de gas natural en A mérica Latina por el país del 2002 al 2003

[Elaboración propia con datos de EIA (2003) (trillones de pies cúbicos) ]

\begin{tabular}{ccc}
\hline País & 2002 & 2003 \\
\hline Venezuela & 149.21 & 148.00 \\
Argentina & 26.78 & 26.96 \\
Bolivia & 27.36 & 24.00 \\
México & $\mathbf{3 8 . 9 5}$ & $\mathbf{8 . 7 8}$ \\
Perú & 8.66 & 8.66 \\
Brasil & 7.86 & 8.09 \\
Colombia & 5.00 & 4.51 \\
\hline
\end{tabular}


mediados del 2000 aparecieron indicios de recuperación y se vislumbraba un incremento continuo de la producción para alcanzar los 8000 millones de pc/d hacia el 2008. La situación real sería un decremento de la producción de gas natural desde 1999. Se considera que este decremento se intensifique después del 2005 al alcanzar su máxima producción en los campos de gas no asociado de la Cuenca de Burgos (YáñezMondragón, 2001), y del tipo asociado en Cantarell (Suárez, 2003). La gráfica de la figura 20 compara los dos escenarios de producción de gas natural; la proyectada del 2000 que preveía incremento de la producción y el real que es en descenso (Figura 20).

Desde el 2003, por la falta de suficiente producción doméstica de gas natural, PEMEX restringe el suministro a la CFE, llegando a 1700 millones de pc, $200 \mathrm{mp} \mathrm{c/d}$ equivalentes a 1,100 MW, que es como la cuarta parte de lo que consume la ciudad de México. Por lo mismo, la CFE empleará el aceite diesel en vez del gas natural en termoeléctricas de tecnología dual (Muñoz, 2003).

\section{Escasas probabilidades de encontrar significativas reservas de hidrocarburos en las aguas profundas del Golfo de México}

Con base en diversos modelos paleogeográficos del Gólfo de México, podemos asumir la casi nula posibilidad de grandes descubrimientos de petróleo y gas natural en sus aguas profundas, debido al acuñamiento de los sedimentos marinos hacia el Oriente. Por otra parte, al Occidente se restringe considerablemente toda posibilidad, al advertir el contacto tectónico de la Trinchera de Chincontepec, propuesta por Bazán (1990) a consecuencia de la colosal cabalgadura de la Sierra Madre Oriental sobre la secuencia de la Planiecie del Golfo de México, condiciones que sellaron su migración definitiva. De hecho, existen otras regiones con mejores posibilidades (Figura 21).

Partiendo de estas ideas podemos arribar a la conclusión de que la actual política energética propicia un alto riesgo en la economía de México, y es cada vez mayor la dependencia en las importaciones de gas natural, debido a los altos consumos que obligan al sector eléctrico, sustentadas con escasas reservas probadas. De acuerdo con la SENER (2003), se proyecta que hacia el 2006 el sector eléctrico consumirá un $37 \%$ del gas natural y en el 2010 el 40.7\%, así como de las importaciones absorberá hacia el 2006 el $26 \%$ y para el 2010 un $50 \%$, cifras que se consideran conservadoras.

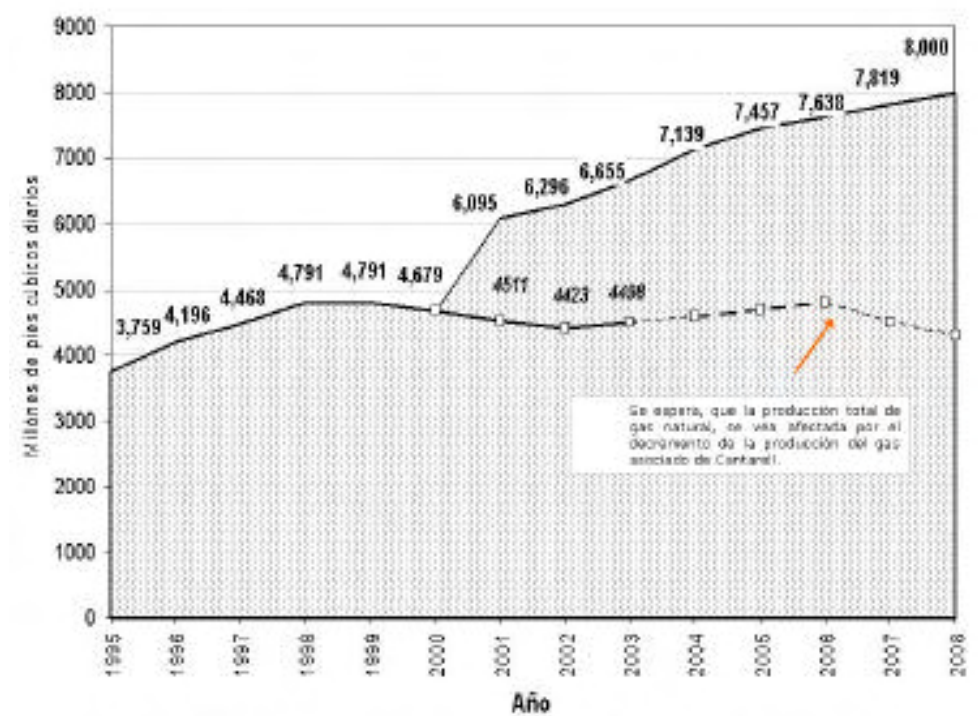

Figura 20. Producción comparativa de gas natural en M éxico, proyección 2000-2008 ascendente y real en descenso

[Elaboración propia con datos de A rriola-Torres (2000), Barbosa-Fabio (2000), Yañez-M ondragón (2001), Suárez-Coppel (2003) y SENER $(2002,2004)$ ] 

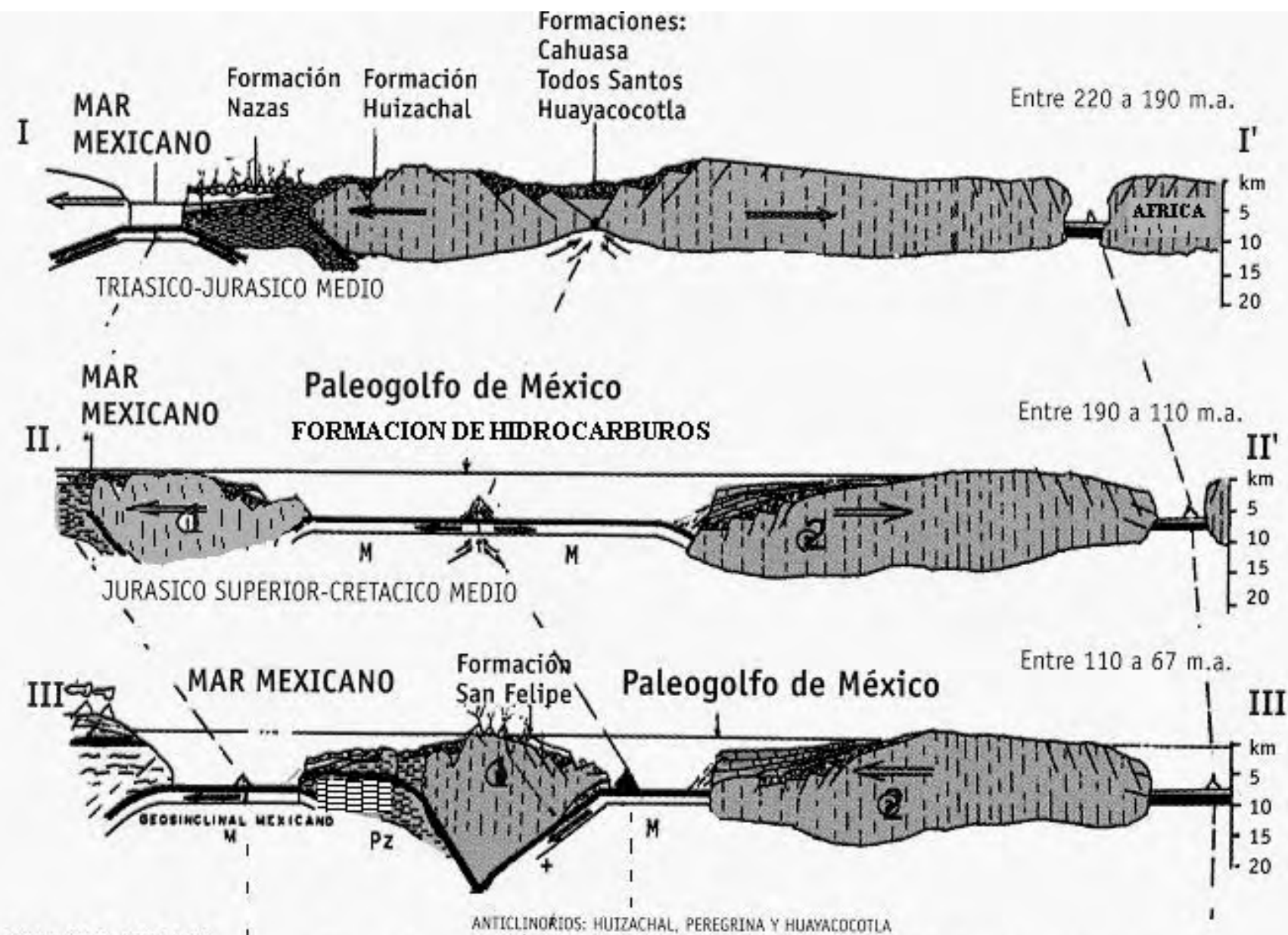

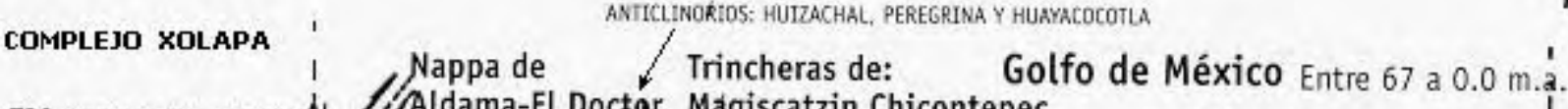

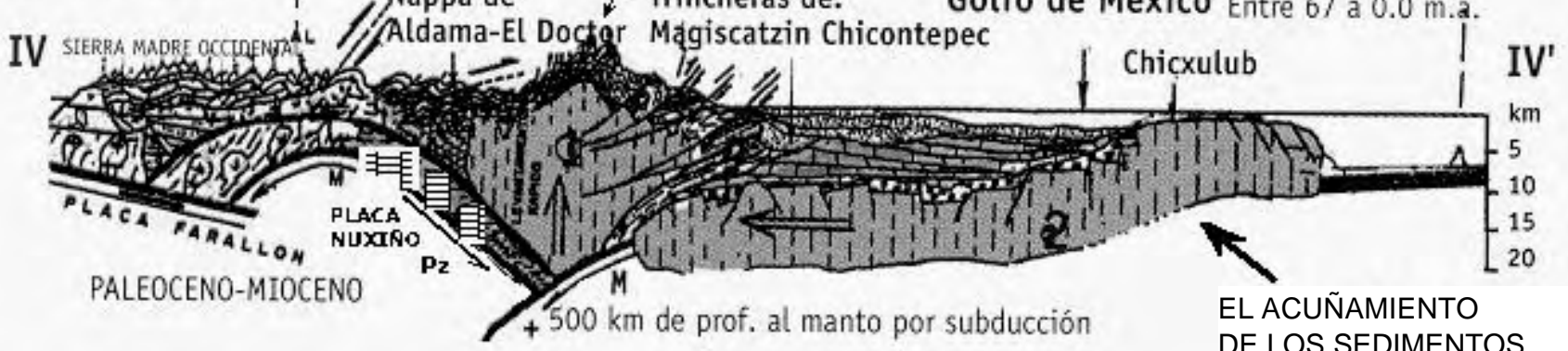

Escudo del Golfo de México (Mexican Shield) del Arqueano

䀧期目 Geosinclinal cordillerano

DE LOS SEDIMENTOS

PETROLÍFEROS AL

ORIENTE, PROPICIA

LA CASI NULA

POSIBILIDAD DE

NUEVOS HALLAZGOS DE

$V / / \begin{aligned} & \text { Rocas precámbrincas pa } \\ & \text { la tectónica nevadiana. }\end{aligned}$

PETRÓLEO Y GAS

NATURAL

1) Gneis Carrisalillo, Gneis Novillo, Gneis Huiznopala, Complejo Daxaqueño y Macizo de Chiapas. Hacia el Poniente en conexión estructural con el Paleozoico cordillerano.

2) Macizos de: Tamaulipas, Tuxpan, Arenque, del Atolón de la Faja de Oro, Tezuitlán, Plan de Las Hayas, del Golfo, de los Tuxtlas yde Yucatán; de la planicie costera del Golfo de México. en subducción hacia el Poniente.-Representan el antepaís de la orogenia mexicana de edad laramide, que se han comportado como plataformas estables desde finales del Paleozoico.- por lo cual, las secuencias Mesozoicas y Cenozoicas que les sobrevacen se presentan en homoclinales.

Figura 21. Evolución geodinámica para el Golfo de M éxico (Bazán-Perkins, 2001) 


\section{Reservas de uranio en México}

El desarrollo de los combustibles nucleares en México constituye un caso singular, desde que las primeras fases de exploración y explotación están bajo control del estado, de esta forma, las fluctuaciones que sufre el precio del uranio en el mercado internacional afectarán la economía nacional en la medida del volumen de reservas probadas, 0 en la carencia de tecnología para producir combustibles que conduzcan al abastecimiento de los programas nucleares. Es de enfatizar, que para el desarrollo de la Industria Nuclear en México, por fortuna se cuenta con potenciales reservas de minerales de uranio susceptibles de ser explotadas, descubiertas y desarrolladas parcialmente hasta la clausura de la empresa paraestatal URAMEX en el año de 1984. En sus respectivas modalidades de potenciales, probables, posibles y probadas. Existen condiciones favorables para incrementar estos rubros a muy corto plazo; pero la escasez de capital y la carencia de tecnología doméstica ocasionó que estas perspectivas quedaran de plano truncadas y olvidadas ante el "boom petrolero" que se desató durante la década de los 80's, originando la debacle de endeudamiento en la que nos encontramos y que aún no se tiene respuesta en el futuro próximo.

En efecto, hacia finales de la administración del Presidente Luis Echeverría Álvarez (1970-1976) la solución programada por el gobierno del país, hacia el 2000, radicaba en emplear principalmente la energía nuclear y sólo un mínimo a los hidrocarburos para la generación de electricidad, no obstante que ya se habían descubierto los campos de Cactus y Cantarell. Lo anterior se fundamentó en un estudio a largo plazo elaborado por la Comisión de Energéticos, al determinar que entre el 2003 y 2005 se alcanzaría la máxima producción de hidrocarburos y el inicio de su descenso (CE, 1976), similar a la prevista por Suárez (2003). Desafortunadamente, la perspectiva de un programa energético a largo plazo quedó en el olvido, lo cual ha sido una de las principales preocupantes (Viqueira, 1979; Fernández-Zayas, 2003).

Desde 1957, se ha venido promoviendo la búsqueda de yacimientos de uranio en el territorio nacional por medio de exploraciones terrestres y reconocimientos aeroradiométricos, lográndose definir más de 200 anomalías radiométricas, entre prospectos y depósitos uraníferos de menor a mayor importancia. Desde entonces, varios distritos regionales investigados como Peña Blanca, Chihuahua, Coneto-El Rodeo, Durango; La ComaBuena Vista, Tamaulipas y Los Amoles, Sonora, formalizaron concentraciones económicas explotables de reservas minerales en los ambientes hidrotermales y sedimentarios. Posteriormente, hacia el cierre de URAMEX se descubrían los gigantescos yacimientos mesozoicos de la Cuenca de Tlaxiaco, estado de Oaxaca (figuras 22 y 23). Los que básicamente vendrían a resolver la problemática de abastecimiento de combustible nuclear para el programa de instalación de plantas nucleoeléctricas (Bazán, 1981).

Hacia los años de 1978 a 1980, de acuerdo con estudios científicos desarrollados por Sergio Bazán Barrón de URAMEX, en un proyecto de tesis doctoral se programó explorar áreas favorables del Jurásico y Cretácico similares a las estudiadas en otros países, desarrollando la infraestructura geológica básica en regiones donde de hecho no existían referencias de manifestaciones uraníferas, pero condiciones favorables que a muy corto plazo resultaran positivas, localizándose las extensas concentraciones diseminadas en terrenos mesozoicos de la región de Tlaxiaco, evidenciando y acreditando así la teoría científica. Fue así como se promovió la exploración de la cuenca mesozoica de Tlaxiaco por medio de brigadas terrestres.

Según Bazán (1981), las brigadas de geólogos a cargo de Ernesto Manjares (1978), a 3 Km al Sur de San Juan Mixtepec, encontraron una anomalía radiométrica en metareniscas del Jurásico Inferior que acusaba entre 1500-2300 cps. Uribe Arriaga (1979) determinó una zona anómala de $950 \mathrm{cps}$ al Sur de Tezoatlán. Finalmente, Vivanco Flores (1980) detectó geológicamente una zona anómala con valores que oscilaran entre 500 y $12,000 \mathrm{cps}$, en el poblado de Santa Catarina Tayata, a unos 20 $\mathrm{Km}$ al No reste de Tlaxiaco, en tobas y areniscas del Mesozoico continental, a partir de $50 \mathrm{cps}$ de fondo radiométrico ambiental litológico. Las figuras 23 y 24, respectivamente, muestran las áreas potencialmente uraníferas pendientes de cubicar al cierre de Uranio Mexicano, entre otras más de la Región de Tlaxiaco, Oaxaca. 


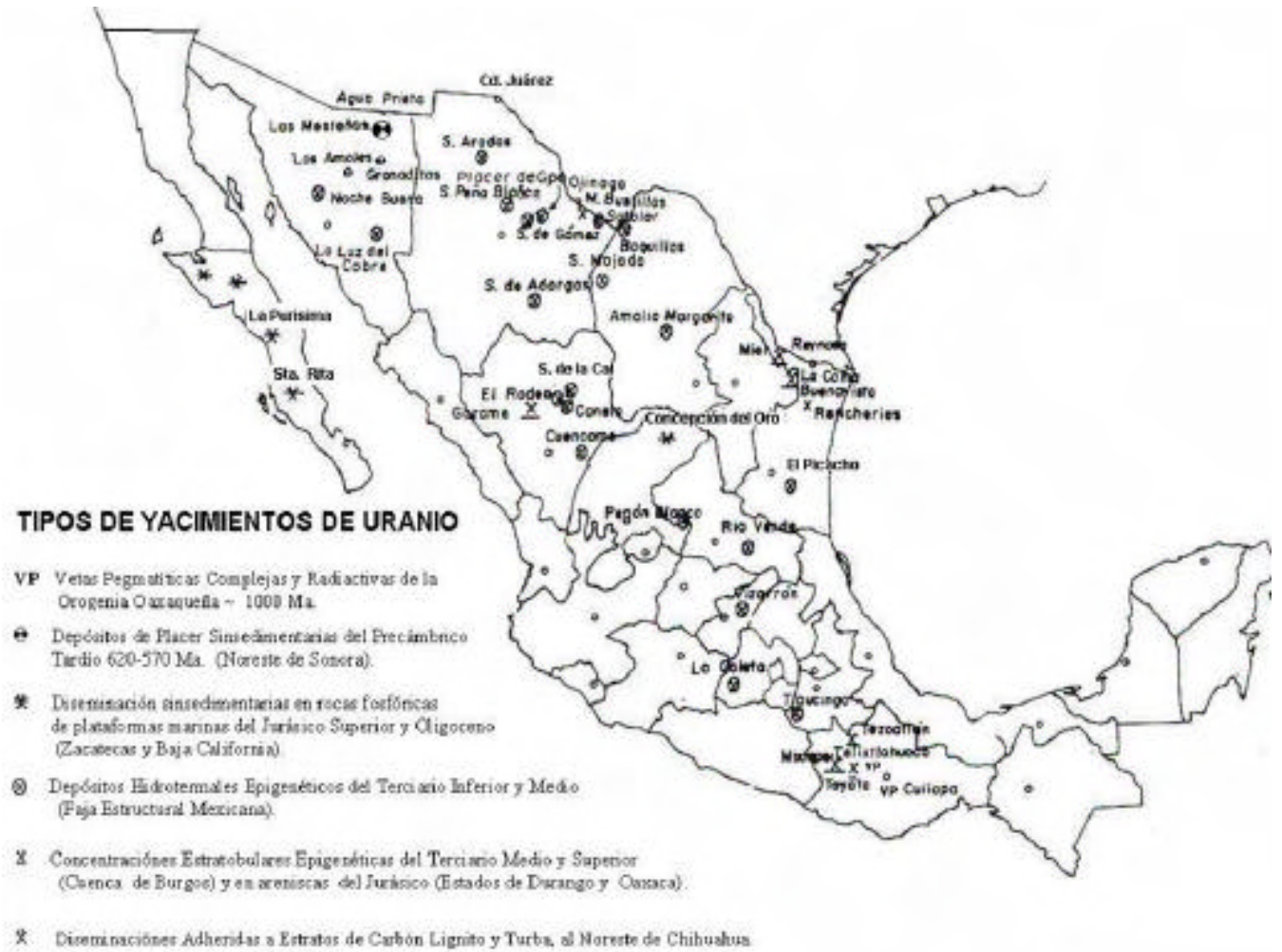

Figura 22. Distribución de los diversos yacimientos de uranio descubiertos en México (Bazán, 1981)

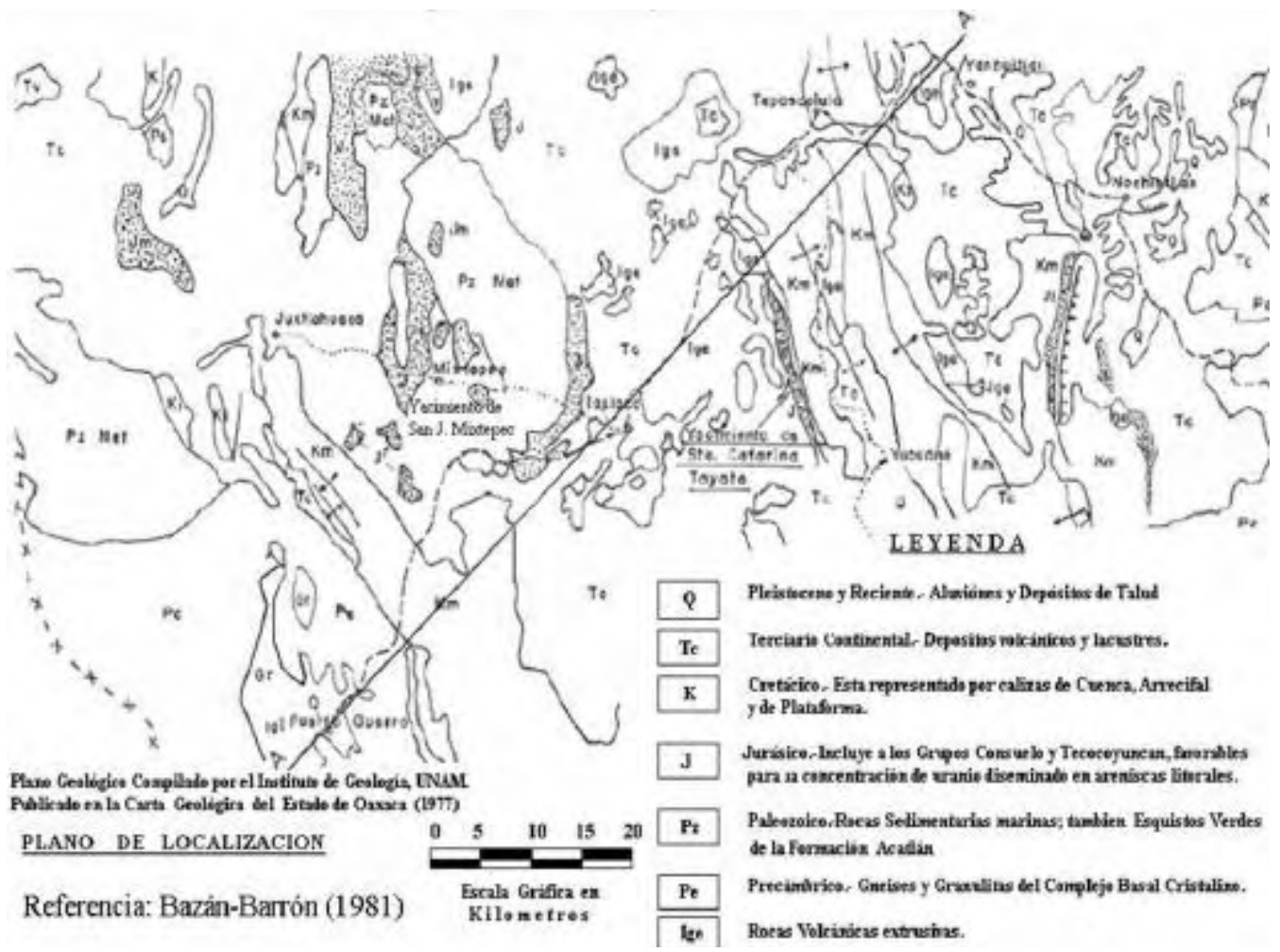

Figura 23. Distribución de las ventanas de erosión del Jurásico infe rior y supe rior de ambiente conti nental y potencialmente uraniferas de la Cuenca de Tlaxiaco, M ixteca alta y Estado de 0 axaca 


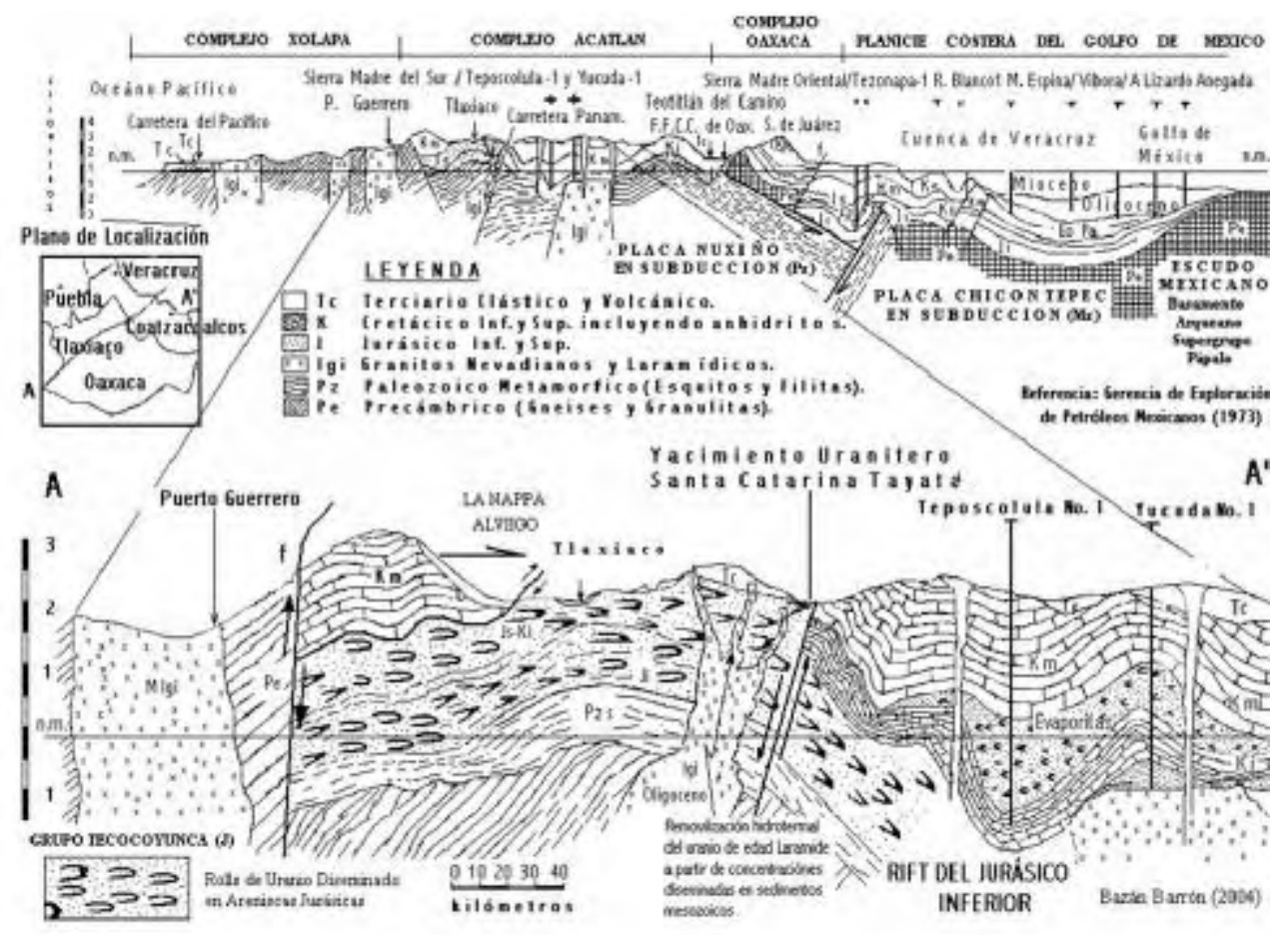

Figura 24. Sección estratigráfica de la cuenca de Tlaxiaco y del Sureste de M éxico, mostrando el área potencialmente uranífera de Santa Catarina Tayata, 0 axaca (Bazán-Barrón, 2004)

Los yacimientos de uranio sedimentario de la Cuenca de Tlaxiaco se encuentran diseminados hacia la base y la cima de secuencias litoestratigráficas del Jurásico y Cretácico continental y litoral, en una faja potencial de $15-20 \mathrm{Km}$ de ancho, con longitud aproximada entre 350-400 Km. Las que comprenden secciones geológicas de 350-550 $\mathrm{m}$ de espesor que afloran esporádicamente, cubriendo el frente continental mesozoico del cartón Precámbrico-Paleozoico denominado Complejo Basal Cristalino de Oaxaca y Guerrero. Estos depósitos se encuentran en condiciones semejantes a los extensos yacimientos sedimentarios del Colorado Plateau de EUA, una de las provincias con mayor riqueza y producción uranífera (Bazán, 1981).

También, como reservas no convencionales, es decir, económicamente no aprovechables pero de gran magnitud como subproducto, serían los depósitos de uranio asociado a depósitos de fosforita en sedimentos de ambientes marinos de la región de San Juan de la Costa y Santo Domingo, Baja California (Escofet et al., 1984; Salas et al., 1988).

Con respecto al potencial y situación económica de las reservas probadas de uranio en
México, podemos partir de las publicaciones de Castañeda (1986) y Salas et al ., (1988), fundados en información técnica de la Comisión Nacional de Energía Nuclear del Instituto Nacional de Energía y de Uranio Mexicano. Si bien, estos profesionistas describen la distribución y características de las reservas uraníferas, su valoración es incierta hasta el año 1981, cuando se contaba con 14,522 t de $\mathrm{U}_{3} \mathrm{O}_{8}$ "in situ" como reservas probables y $35,000 \mathrm{t}$ de posibles, lo que en la práctica se trata de verdaderas estimaciones de $\mathrm{U}_{3} \mathrm{O}_{8}$ difíciles de recuperar comercialmente por su escaso volumen y con gran parte de refractarios para su recuperación metalúrgica, lo que en conjunto elevaban su costo de concentración entre 4 a 8 veces, según el yacimiento; más de lo que se podría adquirir en el mercado internacional.

En resumen, son pocas las reservas probadas de uranio en México, en 1999 las reportadas en la estadística mundial, son de $1,700 \mathrm{t}(\leq 130 \$ \mathrm{US} / \mathrm{Kg}$ de U 308) (Uranium, 2000). Sin embargo, se cuenta con un gran potencial de reservas que en poco tiempo podrían ser cubicadas en detalle y convertirse en reservas probadas de grandes dimensiones, teniendo como principal región a las de la Cuenca Mesozoica de Tlaxiaco (Oaxaca-Guerero). 
Su desarrollo puede colocar a México entre los países con mayores reservas probadas y un mayor interés económico para el desarrollo tecnológico, así como el mejor aprovechamiento energético con participación internacional.

Por lo expuesto, las regiones más favorables de México por sus condiciones potenciales son en primer término, la Cuenca de Tlaxiaco, estado de Oaxaca y Guerrero (Mesozoico); Cuenca de Burgos, Tamaulipas (Terciario); Secuencia Formación Trancas, Querétaro (Mesozoico), las tres en ambientes sedimentarios continentales de litoral. En un segundo término, los yacimientos de uranio asociado a rocas volcánicas e hidrotermales como los del Distrito Uranífero de Villa Aldama, Chihuahua. En tercer término, los no convencionales de San Juan de la Costa y Santo Domingo, Baja California, al obtenerse como subproducto de la roca fosfórica.

\section{Las fuentes renovables versus nuclear para la generación de electricidad}

Al desarrollar México la generación de electricidad basándose en la energía nuclear y renovables, en sustitución de los combustibles fósiles, estaría participando activamente al decremento de los gases de efecto invernadero $\left(\mathrm{CO}_{2}, \mathrm{CH}_{4}, \mathrm{~N}_{2} \mathrm{O}, \mathrm{HFCs}\right.$, PFCs, $\mathrm{SF}_{6}$ ) y en condiciones de competitividad a largo plazo (figura 10 y tabla 1). De hecho, en el 2001 durante el XVIII Congreso Mundial de la Enegía, se concluyó que las únicas fuentes de generación de electricidad capaces de cubrir las necesidades de un país y sin emisiones contaminantes a la atmósfera sería la nucleoeléctrica y la hidroeléctrica (WEC, 2001).

Actualmente, México cuenta con un amplio potencial hidroeléctrico de 53,000 MW de las que se aprovecha el 17\%. En geotérmica, se tienen 950 MW que puede llegar a los 2400 MW. De la eoloeléctrica se cuenta con $3 \mathrm{MW}$, y su potencial es de $3000 \mathrm{MW}$ en el Istmo de Tehuantepec y en la nación alcanza los 5000 MW (SENER, 2002 y 2003). Torres (1969) investigó los sitios ventajosos para construir plantas de generación de electricidad a base de la energía del mar, la desembocadura del Río Colorado y la zona comprendida entre la isla de Tiburón y la tierra firme de Sonora, ambos en el Golfo de California.
En suma, del conjunto de alternativas renovables para la generación de electricidad, como sería la hídrica, eólica, solar, biomasa, mareas, y geotérmica; la única que por sí sola es capaz de generar electricidad en forma masiva para cubrir las necesidades de un país sería la hidroeléctrica. De estas opciones, la única que no depende de la climatología es la geotérmica. Bardwell (1981) concluye que cuando se produce electricidad empleando a la biomasa como energético, se requiere de mayor energía humana con decremento de la productividad y calidad de vida.

Ahora bien, no es valido considerar que todas las fuentes de energía renovables son sustentables y de mercados de "energía verde" cuando en realidad hay varias excepciones como las grandes hidroeléctricas y las "granjas eólicas".

Así, las grandes hidroeléctricas son responsables del descenso de las poblaciones de peces en el Mar Negro, el Mar Caspio, La Bahia de San Francisco, Mar Medierraneo Oriental y Golfo de México. Debido a sus graves impactos a los ecosistemas, varios estados de los Estados Unidos restringen su desarrollo y aceptan las pequeñas $(<30 \mathrm{MW})$, como en Nueva Jersey, Arizona, California, Iowa, Missouri, Maine, Rhode Island. En Missouri no se acepta ninguna generación hidroeléctrica como ambientalmente aceptable. Si se generaliza su restricción en los Estados Unidos, afectaría las exportaciones de electricidad de Canadá y México al obligarlos a regresar a la mesa de negociaciones del Tratado de Libre Comercio (Knight, 2003).

Por otro lado, para intensificar la participación de las fuentes renovables como la hídrica, eólica y solar, cuyo factor de disposición es bajo por depender de la climatología, se requiere de una infraestructura de respaldo para no interrumpir su operación. Es decir, su empleo significa duplicar la infraestructura de generación y una mayor inversión. Las tecnologías de respaldo son las que podrían operar las 24 horas del día todo el año, como son las termoeléctricas con base al carbón mineral, gas, petróleo y nuclear.

En efecto, las "granjas eólicas" requieren al instante que aminore el viento del respaldo de las termoeléctricas, comúnmente a base de combustibles fósiles que emiten gases de efecto invernadero. También por su baja disponibilidad, de un $30 \%$, se necesita construir un gran número de 
unidades; por ejemplo, una planta de ciclo combinado de 1000 MW y de un $80 \%$ de disponibilidad, equivale a instalar 2,666 aerogeneradores de 1 MW. Además, para cada aerogenerador se necesita construir un camino de acceso preferentemente pavimentado, una base de cemento del tamaño de una alberca y línea de alta tensión; lo cual significa afectar grandes extensiones de terreno, impacto visual, perturbación del habitat silvestre, alto ruido, en ocasiones muerte masiva de aves y el transito de vehículos pesados que contaminan el medio (Duchamp 2002).

Finalmente, Rashad y Hammad (2000) concluyen que al emplear la generación nuclear en sustitución de las fuentes de energía a base del gas, petróleo, carbón mineral, hidráulica y eólica, se reduce en gran medida la degradación ambiental, el número de accidentes y muertes humanas, a lo largo de todas las etapas de la cadena energética. Siendo, en consecuencia, el papel fundamental de la energía nuclear la protección del ambiente global. Para el caso de México, Eibenschutz (2001) considera que el desarrollo de la energía nuclear propiciaría seguridad económica, fomento industrial y tecnológico, sustentabilidad y diversificación de fuentes.

No obstante, como lo comentan Bardwell (1981) y Bauer (1984), el desarrollo de las tecnologías de generación de energía de sustitución y diversificación, llave en mano, importadas, resultan ilusorias si no están vinculados a la inversión en capacitación de recursos humanos y de producción de capital propios; siendo esencial maximizar la participación de nuestros sectores públicos, privados y universidades en estos proyectos. De lo contrario, como lo discuten Castañeda-Pérez \& al., (1984), al desarrollar un programa nucleoeléctrico o carboeléctrico implicaría la dependencia tecnológica y de recursos financieros de gran magnitud.

\section{Conclusiones y recomendaciones (Segunda Parte)}

1. Por los resultados de esta exposición, y bajo distintos criterios, se determina que hacia la próxima década la generación de electricidad en México basándose principalmente en los hidrocarburos, será inviable y difícil de sostener por la insuficiencia de sus reservas probadas y sus altos precios. Por tanto, es prioritario reformar el plan energético nacional al otorgarle mayor peso al empleo de la generación nucleoeléctrica y de las fuentes renovables; que implican mayor progreso económico y mejoramiento ambiental para alcanzar la sustentabilidad y competitividad.

2. La política energética, apostada en el gas natural para generar electricidad, está en el umbral de la inviabilidad por la volatilidad y alto precio del gas natural en el mercado. También por las bajas reservas domésticas de gas natural y petróleo, incluyendo sus afectaciones ambientales que provocan en la producción de electricidad.

3. Se recomienda adoptar medidas preventivas para decrementar el consumo de gas en el Sector Eléctrico Mexicano. El programa incluiría la construcción de nuevos parques de aerogeneradores y plantas geotermoeléctricas. Así como el reemplazo de las termo eléctricas que consumen combustibles fósiles por pequeñas instalaciones hidroeléctricas y nucleoeléctricas. Estas cuatro tecnologías, pueden encarar ambas crisis, la ambiental y la de abastecimiento interno de gas natural, a costos de generación competitivos.

4. Por la experiencia que se tiene en México, a partir del descubrimiento y desarrollo de un yacimiento de uranio comercialmente explotable, de origen sedimentario y diseminado en areniscas del Mesozoico (Cuenca de Tlaxiaco, Oaxaca) y del Terciario (Cuenca de Burgos, Tamaulipas), se estiman 10 años para ponerlos en explotación y obtener el Yellow Cake. No obstante, el término de 10 años se puede reducir a 6, considerando las siguientes alternativas:

Primero.- Otorgar concesiones a las empresas mineras mexicanas con tecnología suficiente, y adquirida del extranjero, ya sea en proyectos de coinversión 0 adquisición de patentes, y

Segundo.- Otorgar concesiones a empresas con tecnología de punta para la exploración y explotación de los yacimientos, pagando para el efecto un precio equitativo por $\mathrm{Kg}$ producido de Yellow Cake, en condiciones estándares y de pureza competitiva del comercio internacional. 
5. Las tecnologías de los renovables, y no obstante, sus altos costos para generar electricidad, se deben impulsar para garantizar la seguridad nacional. La energía geotérmica, debe ser desarrollada al máximo, ya que disminuye el nivel de riesgo del portafolio energético por no depender de la climatología y la disposición de combustibles. La energía de la biomasa puede ser la mejor alternativa para áreas especificas del país de clima y suelos fértiles. La energía eólica, tiene importante ventaja logística al incrementar la generación de eléctrica a corto plazo en las áreas geográficas favorables del país; aunque requiere de una planificación cuidadosa para amortiguar sus afectaciones ambientales. Finalmente, la energía hídrica debe procurarse hacia las pequeñas, de menos de 30 MW de capacidad, a fin de favorecer la competitividad en la exportación de electricidad.

6. Se recomienda considerar en los modelos económicos del Sector Eléctrico de México, que el $40 \%$ de las reservas de hidrocarburos (Región Norte) no obedece a las reglas de una economía de mercado, de oferta-demanda, debido a que no están completamente desarrollados e integrados; además, se estimaron en un marco geológico que no es favorable para la explotación.

\section{Referencias (Segunda Parte)}

Arriola T.A. (2001). La tecnología en la estrategia de exploración y explotación del gas natural en M éxico, el Sector Energía en M éxico, de Cara al Siglo XXI. Instituto Mexicano del Petróleo, México.

Barbosa-Fabio (2000). PEMEX: Histórico proyecto de producción gasera, gas natural, México: nueva geografía de petróleo y gas, gas natural. Revista petróleo y electricidad, México.

Bardwell S. (1981). El modelo econométrico La Rouche-Riemann. Revista bimestral Fusión, Vol. 1, No. 1, Enero, USA, pp. 42-55, ISSN 0272-1147.

Bauer M. (1984). A pertura y presentación del foro, Carbón y Uranio como fuentes energéticas en M éxico. Programa Universitario de Energía, UNAM, Reimp. 1990, pp. 17-18.

Bauer M. y Quintanilla J. (2000). Conflicting Energy, Environment, Economy Polices in
México. Energy Policy, 28 (2000), pp. 321-326.

Bazán B.S. (1981). Distribución y metalogénesis de la provincia uranífera del Mesozoico de México. Revista GEOMIMET, No. 112, México, pp. 65-96.

Bazán B.S. (1990). Subducción paleogénica en la margen Oriental de México. $X$ Convención Geológica Nacional, Resúmenes, México.

Bazán B.S. y Bazán-Perkins (2001). El impacto en el Chicxulub, referencias geoló gicas que destruyen la teoría de la extinción de los dinosaurios por impacto de un meteorito, primera parte. Revista GEOM IMET, No.233, México, pp. 6-26.

Benavides G.L. (1956). Notas sobre la geología petrolera de México. XX Congreso Geológico Internacional, México, pp. 350-562.

BP (2001, 2002 y 2003). Statical Review of World Energy, 1965 to 2000, 1965 to 2001, 1965 to 2002.

Campbell C.J. (2000). Peak Oil-a Turning Point for Mankind. Presentation at the Technical University of Clausthal, December.

Castañeda P.M. (1986). La producción de uranio en M éxico, Recursos U raníferos. Programa Universitario de Energía, UNAM, pp.165.

Castañeda P.M., Quintanilla J. y Medina M. (1984). Carbón y uranio como fuentes energéticas en México. Editores y coordinadores. Programa Universitario de Energía, UNAM, Reimp. 1990, México, pp. 9-15 y 19-37.

Comisión de Energéticos (1976). Propuesta de lineamientos de política energética. Secretaría de Patrimonio Nacional, Comisión Federal de Electricidad, Instituto de Energía Nuclear, Petroleos Mexicanos, Gobierno, México, pp. 97.

De la Fuente y Mejia I. (1969). Problemas de la exploración petrolera de la cuenca de Chicontepec. Seminario sobre Exploración Petrolera, IMP, PEMEX, México, pp. 31.

Duchamp M.(2002). Las granjas eólicas como una desgracia para el paisaje. Fundación Argentina de Ecología Científica, España.

EIA (2003). World Crude Oil and Natural Gas Reserves, Most Recent Estimates. International. 
Eibenschutz J. (2001). Energía nuclear. Programa Universitario de Energía. IV Congreso de la Asociación Mexicana Para la Economía Energética, UNAM, México, pp.19

Escofet R.A. y Castillo F.E. (1984). El uranio en M éxico, carbón y uranio como fuentes energéticas en M éxico. Programa Universitario de Energía, UNAM, Reimp. 1990, México, pp. 55-67.

Fernández-Zayas J.L. (2003). Posibilidades actuales del hidrógeno como energético en M éxico. Director General de Investigación y Desarrollo, SENER, México.

Gerber C.R., Hamburger R. y Seabrook H.E.W. (1966). Plowshare. Comision de Energía Atómica de los Estados Unidos, USA, pp. 58.

González-Reyna J. (1956). Riqueza minera y yacimientos minerales en México. Banco de México, S.A., pp.498.

Herman J.A.A., Lowe J. J. y Schoff R.L. (2001). The Economics of $G$ as Turbines in the PJM Region. Department of Energy, National Energy Technology Laboratory, USA, pp.135.

INEGI (1993). Estadísticas históricas de M éxico, Tomo 1, México, pp. 596.

INEGI (2001). El sector energético en M éxico, Estadísticas 2001, México, pp. 289.

INEGI (2002 y 2003). Banco de información económica, oferta interna de energía primaria, México.

Knight D. (2003). Estados Unidos: Canadá resiste plan de energía verde, medio ambiente y desarrollo. Tierraamérica.

Muñoz L. (2003). Cierran el gas a CFE, comentario de Eduardo Andrade (AMEE) y Elias A. (CFE), 02-02-2003, fuente Intélite.

PEMEX (2000, 2001, 2002 y 2003). Memorias de labores 1999.2000, 2001 y 2002, Resultados 0 perativos y Financieros, México.

PEMEX (2001 y 2002). A nuario estadístico 2001 y 2002, informes, México.

PEMEX (2001). Reservas del 2000, anuario Esp, Enero del 2001. Petroleos Mexicanos, México.
Rashad S.M. y Hammad F.H (2000). Nuclear Power and The Environment Comparative Assessment of Environmental and Health Impacts of Electricity-Generating Systems. A pplied Energy, V. 65, Issues 1-4, April 2000, pp. 211-229.

Salas G.P y Castillo N.F. (1988). Geología de los yacimientos uraniferos en México. Geología Económica de México, Ed. Fond. Cult. Econ., pp. 219-224.

SENER (2001). El futuro del sector eléctrico mexicano. Secretaría de Energía, México.

SENER (2002 y 2003). Prospectiva del sector eléctrico 2002-2011 y 2003-2012. Secretaría de Energía, México.

SENER (2002). Prospectiva del mercado del gas natural 2000-2009. Secretaría de Energía, México, pp. 183.

Suárez C.J.J. (2003). Padece declive Cantarell, economía y finanzas. Periódico Reforma, reportaje de Shields David, 20 Enero del 2003, PEMEX, México.

Torres H.F. (1969). Energía y electricidad. Revista Ingeniería, Facultad de Ingeniería, UNAM, México, Vol. XXXIX, No. 1, pp. 69-82.

Uranium (2000 y 2001). Ressources, Production et Demande, OECD. Agence Internationale de I'Energie Ato mique.

Viqueira L.J. (1979). Energéticos: la perspectiva para después del petróleo. Revista Ingeniería, Facultad de Ingeniería, UNAM, Vol. XLIX, No. 4, México, pp. 11-21.

WEC (2001). Borrador de conclusiones y recomendaciones del 18 Congreso Mundial de la Energía. World Energy Council, Argentina.

Yáñez-Mondragón M.E. (2001). La región N orte en el umbral del Siglo XXI, PEMEX. El Sector Energía en M éxico.

\section{Semblanza del autor}

Sergio D. Bazán-Perkins. Realizó la licenciatura en ingeniería geo lógica en la Facultad de Ingeniería de la UNAM, con mención especial. Obtuvo el grado como maestro en ingeniería en investigación de operaciones, orientada a las finanzas en la misma Facultad en donde actualmente cursa el doctorado en el campo de la economía de la energía. Es autor de 45 trabajos publicados en revistas y congresos nacionales e internacionales con arbitraje. Ha ocupado diversos puestos directivos y de supervisión en entidades gubernamentales y privadas. 